FedUni ResearchOnline https://researchonline.federation.edu.au

This is the published version of the following article:

Garg, B., Pearson, P., Cousins, A., Verheyen, V., Puxty, G., Feron, P. (2018) Experimental evaluation of methods for reclaiming sulfur loaded amine absorbents. $14^{\text {th }}$ Greenhouse Gas Control Technologies Conference (GHGT-14); Melbourne, Australia; $21^{\text {st }}-26^{\text {th }}$ October 2018, pp. 1-8.

Copyright (c) 2018.

This is the published version of the work. It is posted here with the permission of the publisher for your personal use. No further use or distribution is permitted. 


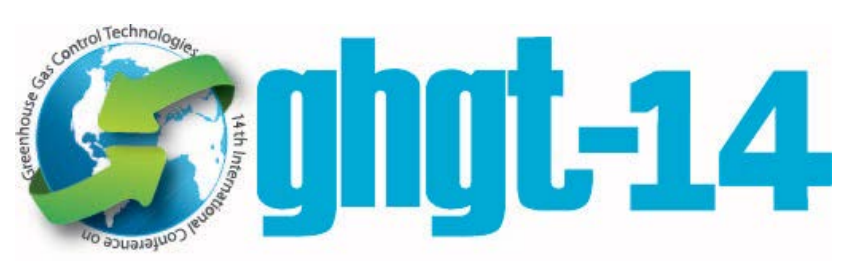

14th International Conference on Greenhouse Gas Control Technologies, GHGT-14

$21^{\text {st }}-25^{\text {th }}$ October 2018, Melbourne, Australia

\title{
Experimental evaluation of methods for reclaiming sulfur loaded amine absorbents
}

\author{
Bharti Garg ${ }^{\mathrm{a}}$, Pauline Pearson ${ }^{\mathrm{b}}$, Ashleigh Cousins ${ }^{\mathrm{c}}$, T Vincent Verheyen ${ }^{\mathrm{a}}$, Graeme Puxty ${ }^{\mathrm{d}}$, \\ Paul HM Feron ${ }^{\mathrm{d}}$
}

\author{
${ }^{a}$ Carbon Technology Research Centre, Federation University, Northways Road Churchill, VIC 3842, Australia \\ ${ }^{b}$ CSIRO Energy, Bayview Avenue, Clayton, VIC 3168, Australia \\ ${ }^{c}$ CSIRO Energy, 1 Technology Court, Pullenvale QLD 4069, Australia \\ ${ }^{d}$ CSIRO Energy, 10 Murray Dwyer Circuit, Mayfield West, NSW 2304, Australia
}

\begin{abstract}
Sulfur dioxide $\left(\mathrm{SO}_{2}\right)$ is a major flue gas contaminant that has a direct effect on the performance of amine-based carbon dioxide capture units operating on power plant flue gases. In many countries, flue gas desulfurisation (FGD) is an essential upstream requirement to $\mathrm{CO}_{2}$ capture systems, thereby increasing the overall operational and capital cost of the capture system. In Australia, the efficacy of $\mathrm{CO}_{2}$ capture may be compromised by the accumulation of $\mathrm{SO}_{2}$ in the absorption solvent. CSIRO's CSCap process is designed to capture of both these acidic gases in one absorption column, thereby eliminating the need for a separate FGD unit which could potentially save millions of dollars. Previous research at CSIRO's post-combustion capture pilot plant at Loy Yang power station has shown that mono-ethanolamine (MEA) solvent absorbs both $\mathrm{CO}_{2}$ and $\mathrm{SO}_{2}$, resulting in a spent amine absorbent rich in sulfates. Further development of the CS-Cap concept requires a deeper understanding of the properties of the sulfate-rich absorbent and the conditions under which it can be effectively regenerated. In the present study, thermal reclamation and reactive crystallisation processes were investigated, allowing the parameters affecting the regeneration of sulfate-loaded amine to be identified. It was found that amine losses were considerably higher in thermal reclamation than in reactive precipitation. During thermal reclamation, vacuum conditions were more effective than atmospheric, and $\mathrm{pH}$ of the initial solution played a significant role in recovery of MEA from the sulfate-rich absorbent. Reactive crystallisation could be effectively accomplished with the addition of $\mathrm{KOH}$. An advantage of this process was that high purity $\mathrm{K}_{2} \mathrm{SO}_{4}$ crystals ( 99\%) were formed, despite the presence of degradation products in the solvent.
\end{abstract}

Keywords: Flue Gas Desulfurisation; Combined capture; CS-Cap concept; Regeneration; Thermal Reclamation; Reactive Crystallsaition

\section{Introduction}

Post-combustion $\mathrm{CO}_{2}$ capture (PCC) through chemical absorption is considered to be one of the most established and effective technologies to be applied in the near future to capture the harmful $\mathrm{CO}_{2}$ emissions from various chemical industries and power stations [1]. Monoethanolamine (MEA) has been demonstrated as a reference absorbent in almost all the research investigations conducted either at lab scale or pilot scale [2]. However, the typical MEA process still faces the challenges including MEA degradation by SOx and NOx, high make-up requirements of fresh aqueous amines, high energy requirements for solvent regeneration and high equipment 
corrosion rates [3]. All these factors ultimately lead to the increased cost of PCC installation in any power station which has a direct impact on the cost of electricity generation [4].

Eighty percent of Australia's electricity generation depends upon coal and the continent has enormous potential for $\mathrm{CO}_{2}$ storage [5]. To continue using its abundant coal resources while achieving the ambitious commitment of reducing emissions by 2030, Australia needs to continue investing in carbon capture and storage to ramp up the technology utilisation from pilot to industrial scale. However, the major challenges are also faced by rest of the world including capital, energy and operating costs.

\subsection{Combined capture of $\mathrm{SO}_{2}$ and $\mathrm{CO}_{2}$}

To make chemical absorption commercially successful, researchers have suggested combined removal of SOx and NOx as one of the practical solutions to lower the high cost involved with the installation of PCC in a power station [3,4]. Experimental evaluation of low cost combined capture techniques has been identified as an important research gap in the commercialisation of this technology [4].

The successful implementation of a PCC facility in Australia is likely to need pre-treatment units like flue gas desulfurization (FGD) which leads to additional capital investments. However, by eliminating the requirement for a separate $\mathrm{SO}_{2}$ removal facility, a combined capture process could provide a cost effective carbon capture solution to Australian coal power.

\subsection{CSIRO’s CS-Cap Process}

In CSIRO's combined capture process “CS-Cap”, $\mathrm{SO}_{2}$ and $\mathrm{CO}_{2}$ are absorbed in a single column with a single absorbent offering huge savings in capital investments [6]. Proof of CS-Cap's combined capture concept has been demonstrated at AGL's Loy Yang power station, Victoria, Australia, details of which have been described in our previous publication [7]. As shown below in Figure 1, $\mathrm{SO}_{2}$ is captured by a small stream with a volume of $0.01-3 \%$ of total MEA in recirculation. The small stream, loaded with $\mathrm{CO}_{2}$ which is drawn from the upper part of the absorber column is used to capture $\mathrm{SO}_{2}$ in the lower part of the absorber column. The stream is continuously recirculated until it is saturated with $\mathrm{SO}_{2}$. Due to the presence of oxygen in the flue gas most of the absorbed $\mathrm{SO}_{2}$ is ultimately converted in to sulfate. Ion Chromatography (IC) analysis confirmed a sulfate loading of $115 \mathrm{~g} / 1000 \mathrm{~g}$ in 3 M MEA used for the pilot plant campaign [7].

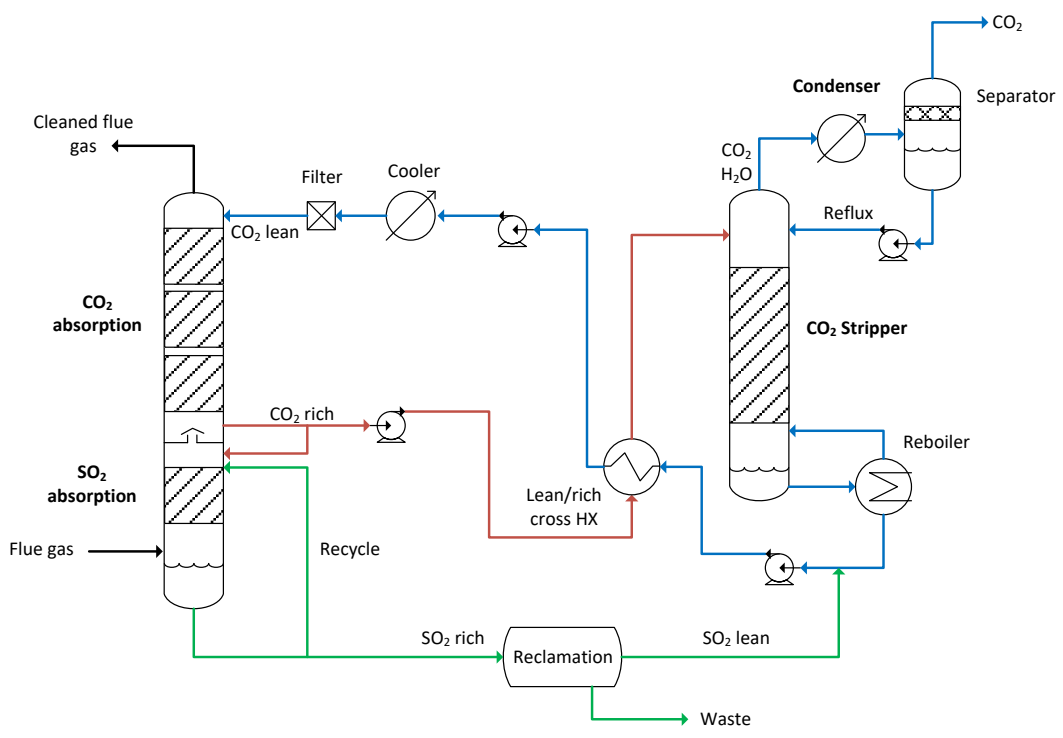

Fig 1: Process flow diagram of the CS-Cap process [7] 


\subsection{Regeneration of absorbent in the CS-Cap process}

Similar to any other PCC regeneration process, the CS-Cap process also faces the challenge of high energy consumption, makeup amine requirements along with formation of heat stable salts [8]. As the process of capturing $\mathrm{CO}_{2}$ during CS-Cap is conventional, the regeneration of $\mathrm{CO}_{2}$ can be done through standard stripping process.However, the unique process design of capturing both the gases within the same absorption column requires regeneration of the sulfur rich MEA stream through other reclamation technologies. Our previous publication on selection and comparison of regeneration technologies evaluated various technologies with the best potential for integration with the CS-Cap's regeneration process [9].Since most of the sulfur absorbed in the CS-Cap process was converted to sulfate, thermal reclamation and reactive crystallisation (precipitation) were found as the best techniques which will be discussed in this paper.

\subsection{Regeneration of sulfate rich stream in the CS-Cap Process}

\section{- $\quad$ Thermal Reclamation}

An initial cost estimation for the thermal reclaimer used to regenerate sulfate rich CS-Cap absorbent stream suggested a relative increase in operating cost by $240 \%$ as compared to a standard thermal reclaimer [9]. The presence of higher heat stable sulfate salts (10-11 wt\%) in the CS-Cap absorbent compared to standard PCC absorbent (usually $2 \mathrm{wt} \%$ ) was considered as the major cause. The amine within these elevated heat stable salts is not recovered through standard stripping process and hence not available for absorption leading to an increased requirement of makeup amine. The increase in the overall cost of the CS-Cap thermal reclaimer against a standard thermal reclaimer was not more than approximately 8 MMUSD for a 900 MW SCPC power station, which is considerably less than the 100's of millions of dollars required to install a separate FGD prior to standard PCC facility. However, this cost estimation was conducted for certain steady state conditions and is not sufficient to provide a true cost comparison given the CS-Cap thermal reclaimer will most likely run continuously at wider operating conditions Given the process composition of the spent CS-Cap absorbent is quite different from the standard spent absorbent out of a PCC + FGD unit; there is a need to confirm if MEA would boil off and be reclaimed under "standard" process operating conditions. Here the experimental evaluation is focussed on identifying the operating conditions under which the bound MEA is released from the heat stable sulfate salts and made available for $\mathrm{CO}_{2}$ and $\mathrm{SO}_{2}$ capture.

\section{- Reactive Crystallisation or Precipitation}

Precipitation or reactive crystallisation was found [9] to be another promising technology for the removal of high levels of sulfate $(115 \mathrm{~g} / 1000 \mathrm{~g})$ in the CS-Cap absorbent. Although reactive crystallisation is not capable of removing all kinds of degradation products, its ability for continuous operation is an advantage. Due to very high levels of sulfate in the CS-Cap absorbent, a continuous regeneration process is an essential requirement of the CSCap process. Reactive crystallisation would involve adding $\mathrm{KOH}$ to the sulfate loaded CS-Cap absorbent, and would produce a potentially saleable by-product, $\mathrm{K}_{2} \mathrm{SO}_{4}$.

\section{Experimental}

\subsection{Sample Preparation and analysis}

CS-Cap sulfate rich MEA absorbent was generated during the pilot campaign run at AGL Loy Yang power station in 2014 [7]. This sulfate rich absorbent is referred to as the "pilot sample" throughout the paper. It has 14 wt\% MEA concentration and $115 \mathrm{~g} / 1000 \mathrm{~g}$ sulfate concentration, unless otherwise specified, e.g. addition of 
degradation products. The initial concentration of aqueous MEA used for the pilot campaign was 18 wt\% which lowered to $14 \mathrm{wt} \%$ after absorption of $\mathrm{SO}_{2}$. "Synthetic samples" refer to aqueous MEA samples prepared in the laboratory from analytical grade reagents. Synthetic aqueous amine samples used for precipitation experiments were pre-saturated with $\mathrm{CO}_{2}$. Sulfate addition was done using concentrated $\mathrm{H}_{2} \mathrm{SO}_{4}$. A Metrohm Ion Chromatograph (IC flex_930) was used to determine amine and sulfate concentrations.

Degradation products were added to the pilot sample to understand their impact on precipitation. Formate, acetate, oxalate were added using formic acid, acetic acid and oxalic acid. The total concentration of these organic anions was $0.83 \mathrm{wt} \%$ as MEA equivalent.

\subsection{Thermal Reclamation Set-up}

Atmospheric distillation was carried out in a three neck flask along with an air cooled condenser and receiver. Heat was supplied via a silicon oil bath and the apparatus was purged with nitrogen. The temperature of the bath and the boiling amine solution was monitored regularly. For vacuum distillation experiments, a rotary evaporator fitted with a recirculating chiller and pump was used.

\subsection{Precipitation method and set-up}

Precipitation experiments were conducted continuously on $\sim 100 \mathrm{ml}$ sulfate loaded aqueous MEA in a beaker heated to desired temperatures using a water bath heater. Top mounted agitators enabled solution/slurry mixing. Excess $\mathrm{KOH}$ against the sulfate present in the solution was added at a fixed intervals at a set temperature. After every addition the solution was stirred for an hour and then stopped to allow the precipitates to settle. A small amount of liquid sample ( $<1 \%$ of total wt of solution) was drawn out of the solution and immediately diluted with water. The liquid sample was analysed by IC to determine the residual sulfate loading in the solution at that particular $\mathrm{KOH}$ addition/temperature. The solution was filtered using vacuum and precipitates were analysed using XRD and ICP_MS.

\section{Results and Discussion}

\subsection{Factors affecting the thermal reclamation of CS-Cap Sulfate rich absorbent:}

- Temperature and Pressure: As expected, pilot samples ( $\mathrm{pH} 12$, initial sulfate loading $115 \mathrm{~g} / 1000 \mathrm{~g}$ ) run under vacuum condition @120-130 ${ }^{\circ} \mathrm{C}$ had comparatively less \% MEA left in the residue than those samples run at atmospheric conditions as shown in Figure 2. The temperature range of $120-130^{\circ} \mathrm{C}$ was chosen to thermally integrate the vapours from the reclaimer with the $\mathrm{CO}_{2}$ stripper column. However, the recoveries remained poor under atmospheric pressure given the boiling point of MEA is $170^{\circ} \mathrm{C}$. Even at temperatures above $170^{\circ} \mathrm{C}$, when subjected to atmospheric pressure the MEA recovery remained poor i.e. more than $70 \%$ of MEA stayed in the residue (from synthetic samples at $\mathrm{pH} 9.5$, the pka of MEA, at $180^{\circ} \mathrm{C}$ ). Furthermore, the effect of temperature is also evident in both Figures $2 \& 3$. The increase of temperature at both vacuum and atmospheric conditions decreased the amount of MEA left in the residue. 


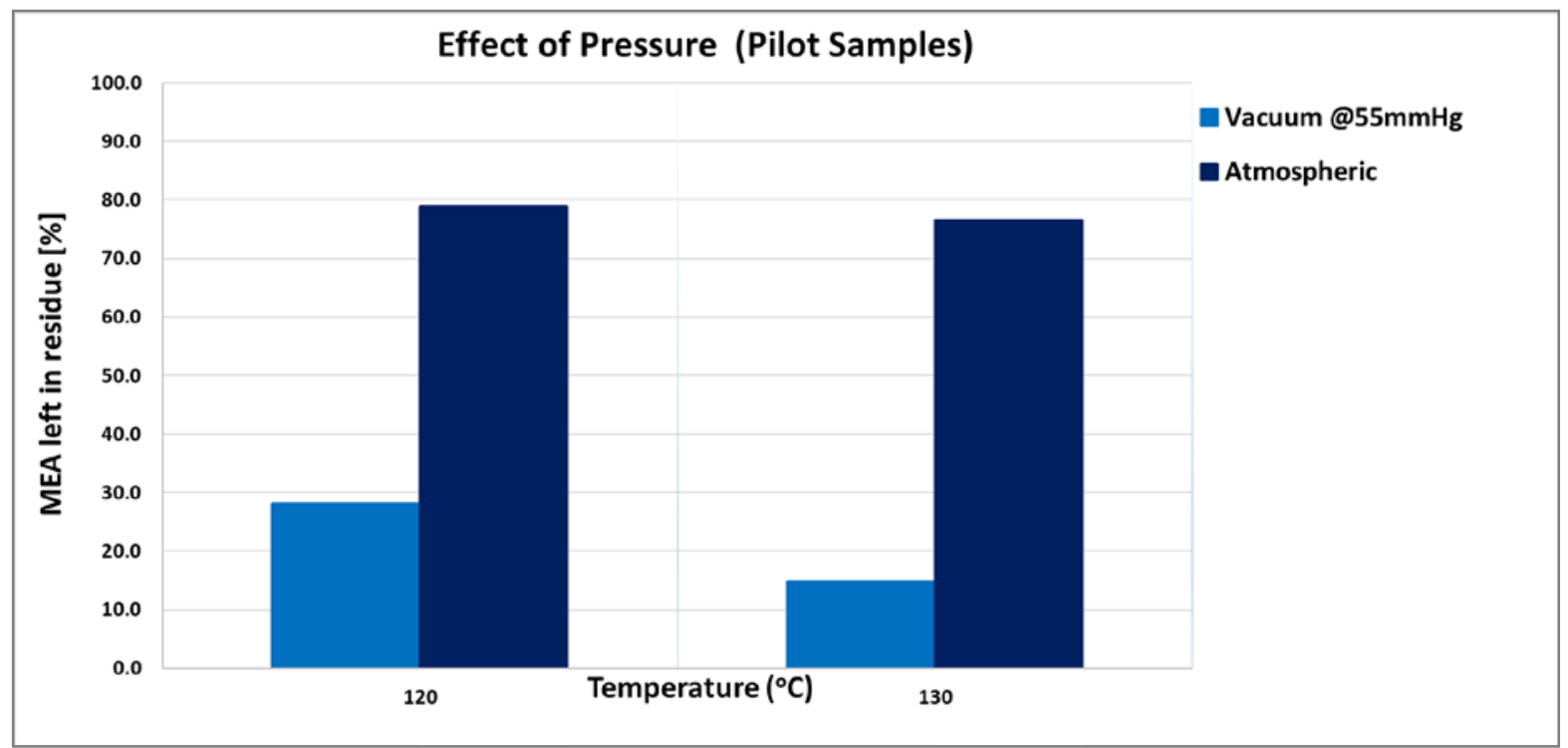

Fig 2: Effect of pressure on thermal reclaiming of pilot plant samples

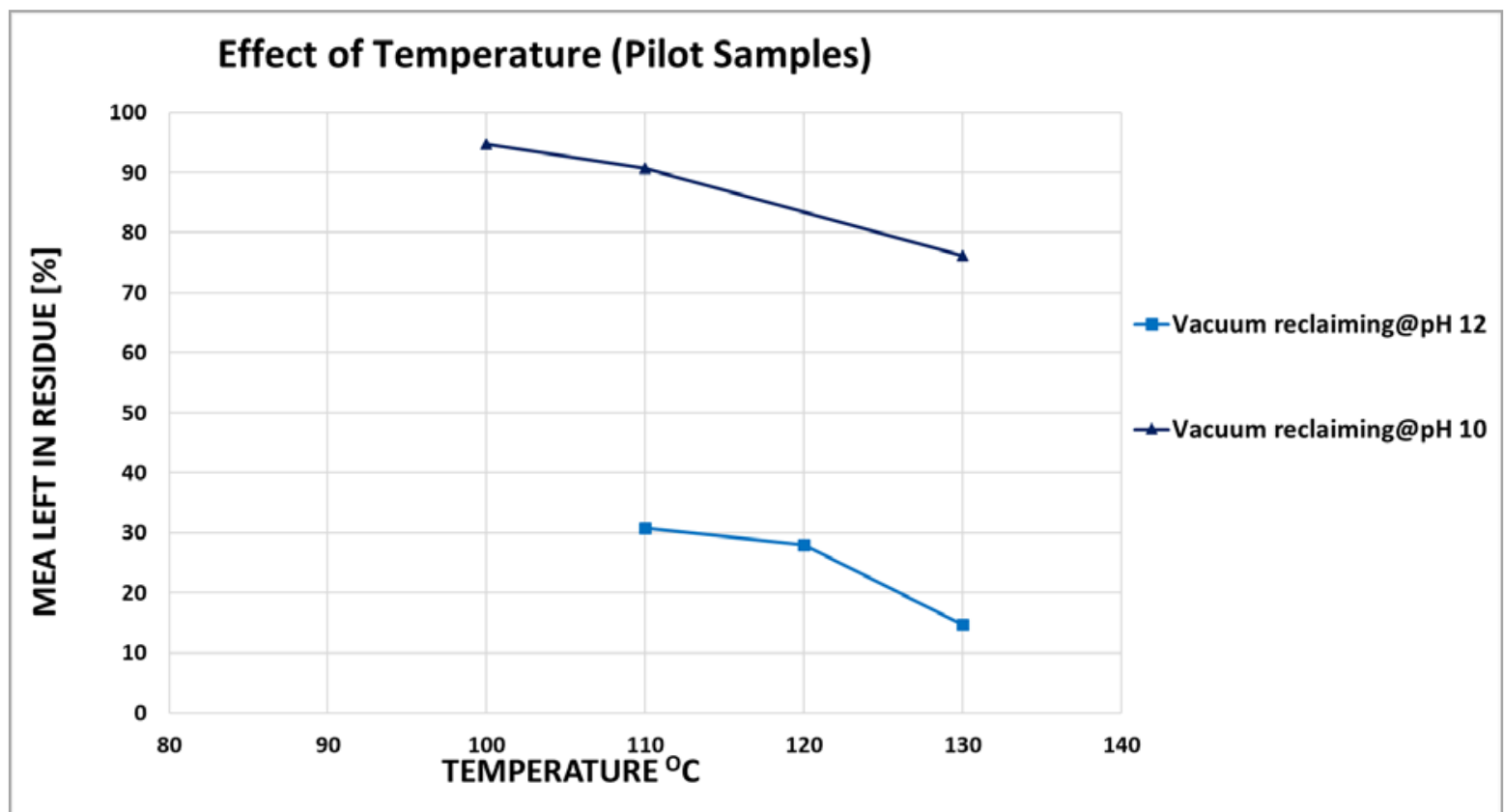

Fig 3: Effect of temperature and $\mathrm{pH}$ on thermal reclaiming of pilot samples

- $\quad$ pH Effect: Initial $\mathrm{pH}$ had a significant effect on the recovery of MEA through thermal reclamation on both pilot and synthetic samples with $14 \mathrm{wt} \%$ MEA concentration. The $\mathrm{pH}$ of the CS-Cap absorbent was near to 4.5 which was raised by adding $50 \mathrm{wt} \% \mathrm{NaOH}$ solution prior to thermal reclaiming. An initial $\mathrm{pH}$ of 9.5 (pKa of MEA) was found to be insufficient for boiling off the amine from the sulfate rich CS-Cap 
absorbent. The presence of high wt\% of heat stable salts of sulfate in CS-Cap absorbent is the probable cause of poor recovery at $\mathrm{pH}$ 9.5. Figure 4 reveals the effect of $\mathrm{pH}$ on both pilot and synthetic samples. At $\mathrm{pH} 12$, more than $85 \%$ of MEA was boiled off from the pilot plant solution. The behaviour of synthetic and pilot samples was found to be quite similar.

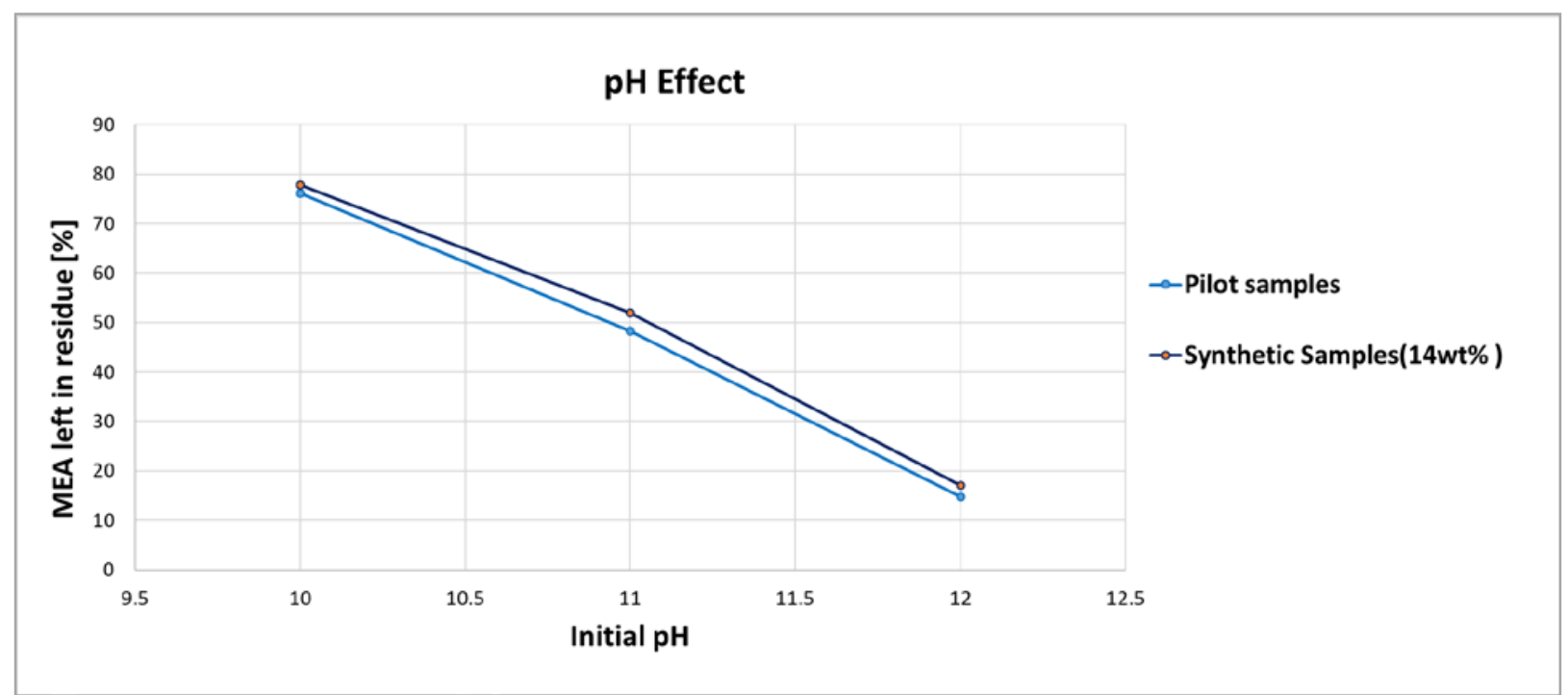

Fig 4: Effect of $\mathrm{pH}$ on thermal reclaiming of pilot and synthetic samples (under vacuum, $55 \mathrm{mmHg}$ at $130^{\circ} \mathrm{C}$ )

\subsection{Factors affecting the reclamation of CS-Cap Sulfate rich absorbent by reactive precipitation}

The various parameters affecting the precipitation of sulfate in the solution include initial sulfate loading, initial MEA concentration, $\mathrm{CO}_{2}$ loading, temperature and amount of excess $\mathrm{KOH}$ added against the sulfate present in the solution. Previous research by Pearson et al., [7] demonstrated the effect of these parameters on the removal of sulfate from pilot and synthetic samples. Here, further experiments confined these parameters to real plant conditions with an improved precipitation method.

- $\quad \% \mathrm{KOH}$ addition: The results in Figure 5 show the effectiveness of precipitation to remove more than $90 \%$ of the sulfate out of the CS-Cap absorbent. As expected, the process did not result in any significant amine losses. The pilot plant samples reveal a similar trend to the synthetic 30wt\% and 40wt\% MEA samples, however, their absolute residual sulfate was higher, due to the known positive effect of amine concentration, where higher concentration results in better sulfate removal as $\mathrm{K}_{2} \mathrm{SO}_{4}$. 


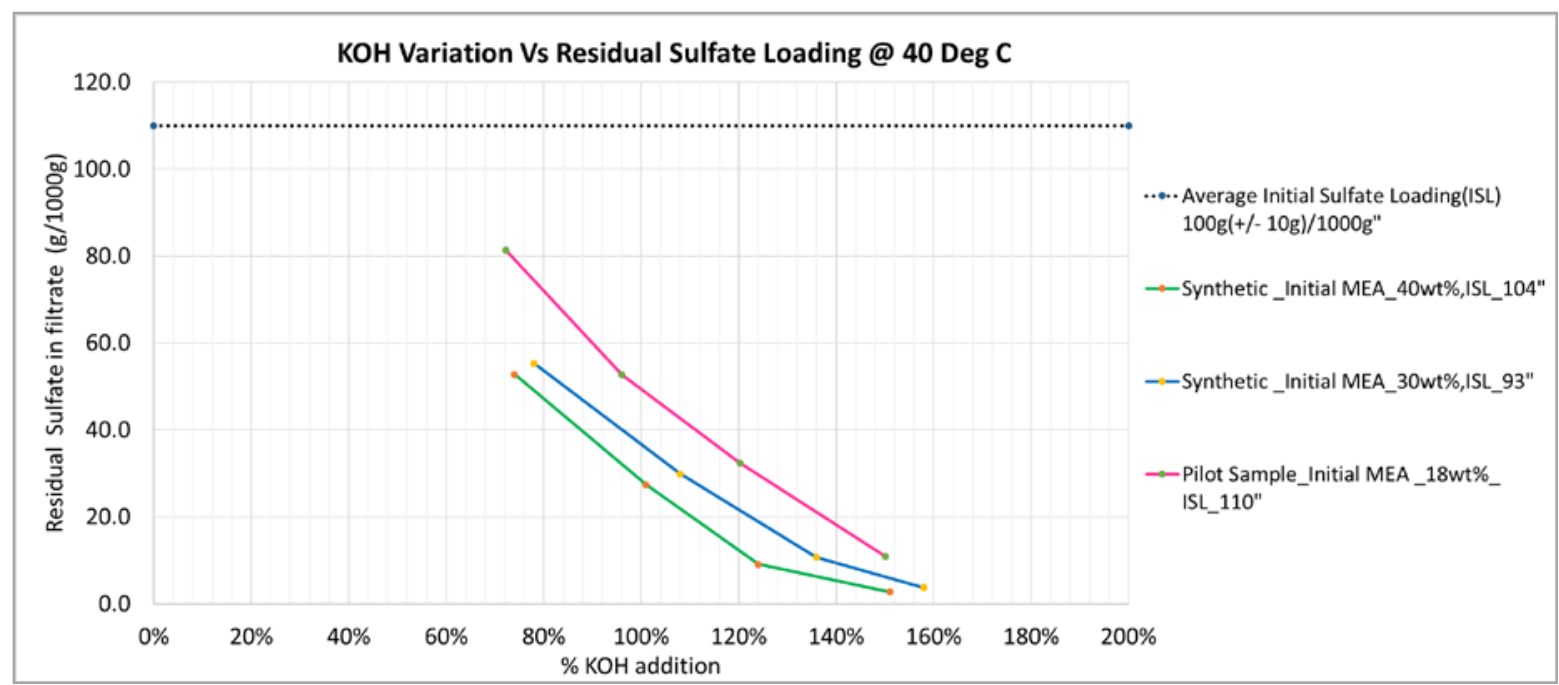

Fig 5: Effect of \% excess $\mathrm{KOH}$ addition on removal of sulfate from pilot and synthetic samples

- Effect of degradation products on precipitation: As a part of the CS-Cap process, a small portion of total recirculating absorbent is used to capture $\mathrm{SO}_{2}$ from the flue gases. After regeneration i.e. $\mathrm{K}_{2} \mathrm{SO}_{4}$ removal, this stream is sent back to main $\mathrm{CO}_{2}$ absorption loop. Hence, there is a high possibility of accumulating other soluble degradation products, apart from sulfate, over time because of ongoing oxidative and thermal degradation. Therefore experiments were conducted to examine the effect of amine degradation on the precipitation of CS-Cap sulfate loaded absorbent as well as on the purity of the precipitates formed. Figure 6 reveals no significant effect from the addition of extra degradation products on sulfate removal. In addition, $\mathrm{XRD}$ analysis of the $\mathrm{K}_{2} \mathrm{SO}_{4}$ crystals formed from the sample with added degradation products were found to be almost pure, $\sim 99 \%$.This is very promising for the saleability of the crystals.

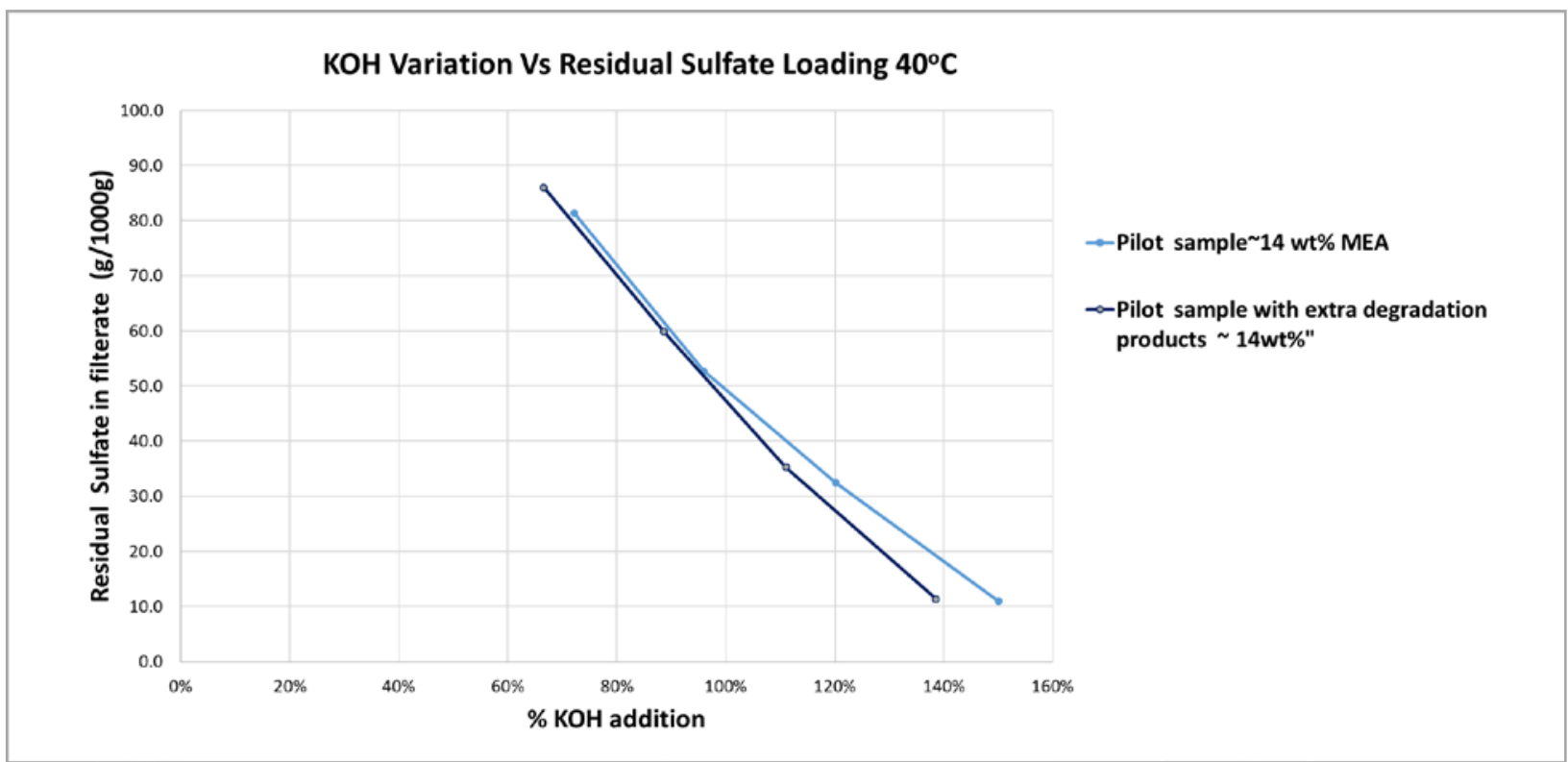

Fig 6: Effect of oxidation and thermal degradation products (formate, acetate and oxalate, total 0.83 wt\% as MEA equivalent) on precipitation of sulfate from the pilot sample 


\section{Future work}

In contrast to thermal reclamation, reactive crystallisation resulted in lower amine losses with almost no waste residue. It appears a better technology for regeneration of CS-Cap sulfate rich MEA absorbent. However, due to the likely variation of flue gas $\mathrm{SO}_{2}$ concentration, the sulfate concentration in the spent CS-Cap absorbent will change. Therefore it is essential to understand the effect of increased sulfate loading on both regeneration techniques. Initial experiments reveal that increased initial sulfate loading on the absorbent will increase the \% of MEA in thermal reclamation residues whereas it decreases the residual sulfate concentrations in precipitation. However more experiments are still planned to understand the impact of the sulfate loading on the performance of both techniques.

A simulation model has been prepared in Aspen Plus for the economic comparison of both the techniques. The laboratory scale experimental data has been fed into the model to review the accuracy of the model. The regeneration technique models will be fitted in to the CS-Cap process model, for an overall economic comparison of the CS-Cap process (with regeneration) to a standard PCC unit + FGD.

\section{Acknowledgements}

The authors wish to acknowledge financial assistance provided by Brown Coal Innovation Australia Limited, a private member-based company with funding contracts through Australian National Low Emissions Coal Research and Development Ltd (ANLEC R\&D) and the Victorian State Government. Bharti Garg is supported by an Australian Government Research Training Program (RTP) Fee-Offset Scholarship through Federation University Australia. Stafford McKnight and Jo-ann Larkins (Federation University) are acknowledged for providing their assistance during this research work.

\section{References}

[1] Wang Y, Zhao L, Otto A, Robinius M, Stolten D. A Review of Post-combustion $\mathrm{CO}_{2}$ Capture Technologies from Coal-fired Power Plants. Energy Procedia 2017;114:650-65.

[2] Salazar J, Diwekar U, Joback K, Berger AH, Bhown AS. Solvent selection for post-combustion $\mathrm{CO}_{2}$ capture. Energy Procedia. 2013;37:257-64.

[3] Wu X, Yu Y, Qin Z, Zhang Z. The advances of post-combustion $\mathrm{CO}_{2}$ capture with chemical solvents: Review and guidelines. Energy Procedia. 2014;63:1339-46.

[4] IEAGHG. Incorporating Future Technological Improvements in Existing $\mathrm{CO}_{2}$ Post Combustion Capture Plants: Technical Review. 2013/Tr5. 2013.

[5] Feron P, Paterson. L. Reducing the costs of CO2 capture and storage (CCS). CSIRO.2011;(March). http://www.garnautreview.org.au/update-2011/commissioned-work/reducing-costs- $\mathrm{CO}_{2}$-capture-storage.pdf

[6] Puxty G, Wei SCC, Feron P, Meuleman E, Beyad Y, Burns R, et al. A novel process concept for the capture of $\mathrm{CO}_{2}$ and $\mathrm{SO}_{2}$ using a single solvent and column. Energy Procedia. 2014;63:703-14.

[7] Pearson P, Moscatelli J, Garg B, Cousins A, Meuleman E, Puxty G,. An update on the development of the CSIRO 's CS-Cap combined $\mathrm{CO}_{2}$ and $\mathrm{SO}_{2}$ capture process. Energy Procedia. 2017;114:1721-8.

[8] Rosli A, Ahmad AL, Lim JK, Low SC. Advances in Liquid Absorbents for $\mathrm{CO}_{2}$ Capture : A Review. Journal of Physical Science. 2017;28:121-44.

[9] Garg B, Verheyen TV, Pearson P, Feron P, Cousins A. A technology review for regeneration of sulfur rich amine systems. International Journal of Greenhouse Gas Control. 2018;75:243-53. 